\title{
Second allogeneic transplants for multiple myeloma: a report from the EBMT Chronic Malignancies Working Party
}

\author{
Patrick J. Hayden $\mathbb{( 1 )}^{1} \cdot$ Dirk-Jan Eikema ${ }^{2} \cdot$ Liesbeth C. de Wreede $^{3} \cdot$ Linda Koster $^{4} \cdot$ Nicolaus Kröger $^{5}$. \\ Hermann Einsele ${ }^{6} \cdot$ Monique Minnema $^{7}$ - Alida Dominietto ${ }^{8} \cdot$ Michael Potter $^{9} \cdot$ Jacob Passweg $^{10}$. \\ Arancha Bermúdez ${ }^{11}$. Stephanie Nguyen-quoc ${ }^{12}$ - Uwe Platzbecker ${ }^{13} \cdot$ Johanna Tischer $^{14} \cdot$ Fabio Ciceri $^{15}$. \\ Joan Hendrik Veelken $\left(\mathbb{D}^{16}\right.$. Per Ljungman $\left(\mathbb{D}^{17}\right.$. Nicolaas Schaap ${ }^{18}$. Edouard Forcade ${ }^{10}{ }^{19}$. \\ Angelo Michele Carella ${ }^{20}$. Virginie Gandemer ${ }^{21} \cdot$ William Arcese $\mathbb{( D}^{22} \cdot$ Adrian Bloor $\mathbb{D}^{23} \cdot$ Attilio Olivieri $^{24}$. \\ Laure Vincent $\mathbb{C}^{25} \cdot$ Meral Beksac ${ }^{26} \cdot$ Stefan Schönland $\mathbb{D}^{27} \cdot$ Ibrahim Yakoub-Agha $\mathbb{C}^{28}$
}

Received: 25 November 2020 / Revised: 9 March 2021 / Accepted: 25 March 2021 / Published online: 11 May 2021

(c) The Author(s) 2021. This article is published with open access

\begin{abstract}
The EBMT Chronic Malignancies Working Party performed a retrospective analysis of 215 patients who underwent a second allo-HCT for myeloma between 1994 and 2017, 159 for relapse and 56 for graft failure. In the relapse group, overall survival (OS) was 38\% (30-46\%) at 2 years and 25\% (17-32\%) at 5 years. Patients who had a HLA-identical sibling (HLAid-Sib) donor for their first and second transplants had superior OS (5 year OS: HLAid-Sib/HLAid-Sib: 35\% (24-46\%); Others 9\% (0-17\%), $p<0.001)$. There was a significantly higher incidence of acute grade II-IV GvHD in those patients who had also developed GvHD following their initial HLA-identical sibling allo-HCT (HLAid-Sib/HLAid-Sib: 50\% (33-67\%); Other 22\% (8-36\%), $p=0.03)$. More as opposed to fewer than 2 years between transplants was associated with superior 5 -yr OS (31\% (21-40\%) vs. $10 \%(1-20 \%), P=0.005)$. On multivariate analysis, consecutive HLA-identical sibling donor transplants conferred a significant OS advantage $(0.4(0.24-0.67), p<0.001)$. In the graft failure group, OS was $41 \%$ at 2 years. In summary, a second allo-HCT using a HLA-identical sibling donor, if available, provides the best transplant outcomes for relapsed myeloma in this setting.
\end{abstract}

Patrick J. Hayden

phayden@stjames.ie

1 Department of Haematology, Trinity College Dublin, St. James's Hospital, Dublin, Ireland

2 EBMT Statistical Unit, Leiden, The Netherlands

3 Department of Biomedical Data Sciences, LUMC, Leiden, The Netherlands

4 EBMT Data Office Leiden, Leiden, The Netherlands

5 University Hospital Eppendorf, Hamburg, Germany

6 Universitätsklinikum Würzburg, Würzburg, Germany

7 University Medical Center Utrecht, Utrecht, The Netherlands

8 IRCCS Ospedale Policlinico San Martino, Genova, Italy

9 Royal Marsden Hospital, London, UK

10 University Hospital, Basel, Switzerland

11 Hospital Universitario Marqués de Valdecilla, Santander, Spain

2 Hopital la Pitié-Salpêtrière, Paris, France

13 Medical Clinic and Policinic 1, Leipzig, Germany

14 Klinikum Grosshadern, Munich, Germany
15 Ospedale San Raffaele s.r.l., Milano, Italy

16 Leiden University Hospital, Leiden, The Netherlands

17 Karolinska University Hospital, Stockholm, Sweden

18 Radboud University Medical Centre, Nijmegen, The Netherlands

19 CHU Bordeaux, Pessac, France

20 Casa Sollievo della Sofferenza, San Giovanni, Italy

21 Centre Hospitalier Universitaire de Rennes Hôpital sud, Rennes, France

22 Rome Transplant Network "Tor Vergata" University of Rome, Rome, Italy

23 Christie NHS Trust Hospital, Manchester, UK

24 Azienda Ospedali Riuniti di Ancona, Ancona, Italy

25 CHU Lapeyronie, Montpellier, France

26 Ankara University Faculty of Medicine, Ankara, Turkey

27 Medical Department V, University Hospital Heidelberg, Heidelberg, Germany

28 Univ. Lille, CHU Lille, INSERM, Infinite, U1286, Lille, France 


\section{Introduction}

Although allogeneic haematopoietic cell transplantation (allo-HCT) is not routinely performed in patients with multiple myeloma (MM), this approach is still offered to patients with high-risk disease. According to the EBMT database, there were $2684 \mathrm{MM}$ patients transplanted in EBMT centres between 2013 and 2018. Post-transplant relapse remains the main cause of treatment failure. Options for the treatment of disease relapse following allo-HCT include salvage chemotherapy, novel targeted agents, and, increasingly, immunotherapies [1-4]. In selected patients who achieve clinical remission, there may be a role for a second allo-HCT [5-10].

The first reports of outcomes following second allogeneic transplants to treat disease relapse were characterised by prohibitively high rates of non-relapse mortality (NRM) of up to $45 \%$ [11, 12]. Less toxicity was seen with the use of reduced intensity conditioning (RIC) regimens. Shaw and colleagues performed a retrospective U.K. multi-centre analysis of 71 patients receiving a second allogeneic transplant using RIC after disease relapse following an initial myeloablative allo-HCT [5]. The predicted overall survival (OS) and NRM at 2 years were $28 \%$ and $27 \%$, respectively. In a subsequent EBMT registry study of 234 adult patients with acute leukaemia who received a second RIC transplant between 2000 and 2012 as salvage treatment for relapse following an initial RIC allo-HCT, the cumulative NRM and OS rates at 2 years were $22.4 \%$, and $20.5 \%$, respectively [6].

In a 2015 retrospective EBMT study of 2632 second allogeneic transplants performed to treat disease relapse following a first transplant, the factors associated with better survival included the use of a HLA-identical sibling donor for the second transplant, low disease burden, longer remission duration after the first transplant, a longer interval between the transplants, younger age, the absence of grade II-IV acute graft-versus-host disease (GvHD) or chronic GvHD after the first transplant, and later year of transplant [13]. There was no difference in overall survival (OS) between those transplanted using their original donors when compared to those who were transplanted using new donors.

Second allogeneic transplants have also been performed to treat graft failure. Ferra and colleagues reported a 5 year OS of $31 \%$ in eighty patients who underwent a second transplant for graft failure [14]. Neutropenic patients and those transplanted using a second unrelated donor fared less well $[15,16]$.

There has, to date, only been one small report specifically relating to second allogeneic transplants in patients with myeloma following either disease relapse or graft failure [17]. We, therefore, performed a retrospective analysis of
215 patients with myeloma who underwent second allogeneic transplants between 1994 and 2017.

\section{Methods}

\section{Study design}

This study was performed in accordance with the principles of the Declaration of Helsinki and was approved by the EBMT, a nonprofit, scientific society representing more than 600 transplant centres, mainly in Europe. All data is stored in a central database. Patients' informed consent was obtained locally according to regulations. The study cohort consisted of 215 patients with myeloma who were reported to the EBMT registry as having undergone a second alloHCT either for relapsed myeloma or for graft failure. Second transplants performed for donor-derived haematological malignancies were excluded. The data were obtained from the EBMT data registry.

Available donor information is categorized as either HLA-identical sibling (HLAid-Sib) or other, the latter group being composed of matched related and unrelated and mismatched related and unrelated donors.

Disease stage was classified using the EBMT registry nomenclature regarding remission status at HSCT. Patients were classified as having either Low (PR or better) or Advanced (SD, MR, relapse, progression, primary refractory/ no CR) stage disease, in this case, myeloma. In other words, patients with myeloma in less than a partial remission pretransplant were considered to have advanced stage disease.

The primary outcomes of interest were OS, non-relapse mortality (NRM), relapse/progression, relapse/progressionfree survival (PFS), and causes of death. Outcomes are provided at 2 or 5 years after the second HCT, depending on the availability of a sufficient number of patients in each of the subgroups of interest. OS and PFS were estimated using the Kaplan-Meier product limit estimation method, and differences in subgroups were assessed by the Log-Rank test. Median follow-up was determined using the reverse Kaplan-Meier method.

The cumulative incidence of relapse and NRM were analysed together in a competing risks framework. Neutrophil engraftment was defined as an absolute neutrophil count $\geq 0.5 \times 10^{9} / \mathrm{L}$ for three consecutive days. The cumulative incidence of neutrophil engraftment is provided at day 28 after the second transplant, with the competing event being death without neutrophil engraftment. Competing risks analyses were also applied to estimate the incidences of acute grade II-IV GvHD and limited and extensive chronic GvHD (cGvHD), by day 100 and 2 and 5 years, respectively. Subgroup differences in cumulative incidences were assessed using Gray's test. 
Multivariable Cox regression was applied to investigate the simultaneous impact of multiple covariates on outcomes, when a sufficient number of patients and subsequent events were available. For OS and PFS, hazard ratios are provided, whereas for the competing risks outcome relapse, cause-specific hazard ratios are provided for the events of interest, both denoted as HR. Included covariates were used in all outcomes: Patient age at second transplant (in decades), patient sex, donor type (HLA identical sibling at both first and second transplant versus other), interval between first and second transplant (years), disease risk (low versus advanced), conditioning intensity (reduced versus myeloablative) and any previous GvHD (no versus yes). All models are stratified by categorized year of second transplant $(\leq 2008,>2008)$.

Continuous variables are presented in text as median (range) and categorical variables as percentages within the group of patients with available data. All estimates are reported with corresponding $95 \%$ confidence intervals in parentheses. All $p$ values were two-sided and $p<0.05$ was considered significant. Statistical analyses were performed in $\mathrm{R}$ version 3.6.0 ( $\mathrm{R}$ Development Core Team, Vienna, Austria), using packages 'survival', 'prodlim' and 'cmprsk'.

\section{Results}

Patient characteristics in the relapse $(n=159)$ and graft failure $(n=56)$ cohorts are shown in Table 1A.

The number of transplants performed in each 5-year period for relapsed and graft failure patients is shown in Table 1B.

\section{Patients transplanted for relapsed MM}

The median time from diagnosis to transplant was 16 (3-150) months for the first transplant and 69 (9-214) months for the second transplant.

In the relapse cohort of 159 patients, 86 had two HLAidentical sibling donor transplants and 70 had other donor types. Data was not available for three patients. Of the 86 classified as having had 'two HLA-identical sibling donor' transplants, information on whether they were transplanted using the same or a different donor was available in 42 of the 86 cases; a total of 35 (83\%) had two consecutive transplants from the same HLA-identical sibling donor and seven (17\%) has two different HLA-identical sibling donors. Of the 70 patients who had other donor types, information on whether they were transplanted using the same or a different donor was available in 59 of the 70 cases. A total of $51(86 \%)$ had different donors for the two transplants. There were eight patients $(14 \%)$ who were transplanted from the same donor of 'other donor type'.

\section{Conditioning and GVHD prophylaxis}

Conditioning regimens used in patients with relapsed disease were mostly fludarabine-based, included Fludarabine and Busulphan \pm ATG $(27 \%)$, Fludarabine and Melphalan \pm ATG $(22 \%)$, and Fludarabine and Treosulphan \pm ATG (9\%). Other regimens included Bulsulphan and Cyclophosphamide \pm ATG (14\%) and Busulphan and Melphalan \pm ATG $(8 \%)$.

GVHD prophylaxis consisted of cyclosporin-based approaches in $83 \%$ of patients in whom data was available, including cyclosporin and methotrexate (MTX) (42\%) and cyclosporin and mycophenolate mofetil (MMF) (35\%).

\section{GvHD}

The rates of acute and chronic GVHD following the second transplant are shown in Table 1C.

When those patients with relapsed myeloma who had two consecutive HLA-identical sibling donor transplants $(n=86)$ were compared to all other donor combinations $(n$ $=70$ ), there was no difference in the rates of acute grade IIIV GvHD (HLAid-Sib/HLAid-Sib 34\% (23-45\%) versus other 25\% (14-36\%) $(P=0.2))$.

When outcomes were then stratified based, firstly, on the presence or absence of GVHD following the first transplant and, secondly, on whether patients had had two HLAidentical sibling donor transplants as opposed to other donor combinations, there was a significantly higher incidence of acute grade II-IV GvHD in patients with prior GvHD who proceeded to a second HLA-identical sibling donor transplant (HLA-HLA: 50\% (33-67\%) vs. Other 22\% (14-36\%), $p=0.03)$.

\section{Overall survival}

Univariate analysis of factors potentially affecting Overall Survival (OS) are shown in Table 2. OS was 38\% (CI $30-46 \%$ ) at 2 years post-transplant and $25 \%$ (CI 17-32\%) at 5 years (Fig. 1a). There was no difference in OS between male and female patients. OS at 5 years was significantly superior when HLA-identical sibling donors were used for both transplants, compared to other donor types (35\% $(24-46 \%)$ vs. $9 \%(0-17 \%), p<0.001)$ (Fig. 1b). Significantly inferior OS was also seen in those who proceeded to a second allo-HCT within 2 years when compared to those who were re-transplanted more than 2 years later $(10 \%(1-20 \%)$ vs. $31 \%(21-40 \%)$ at 5 years, $P=0.005)$ (Fig. 1c).

\section{Progression-free survival}

Univariate analysis of factors potentially affecting Progression-Free Survival (PFS) are shown in Table 2. 


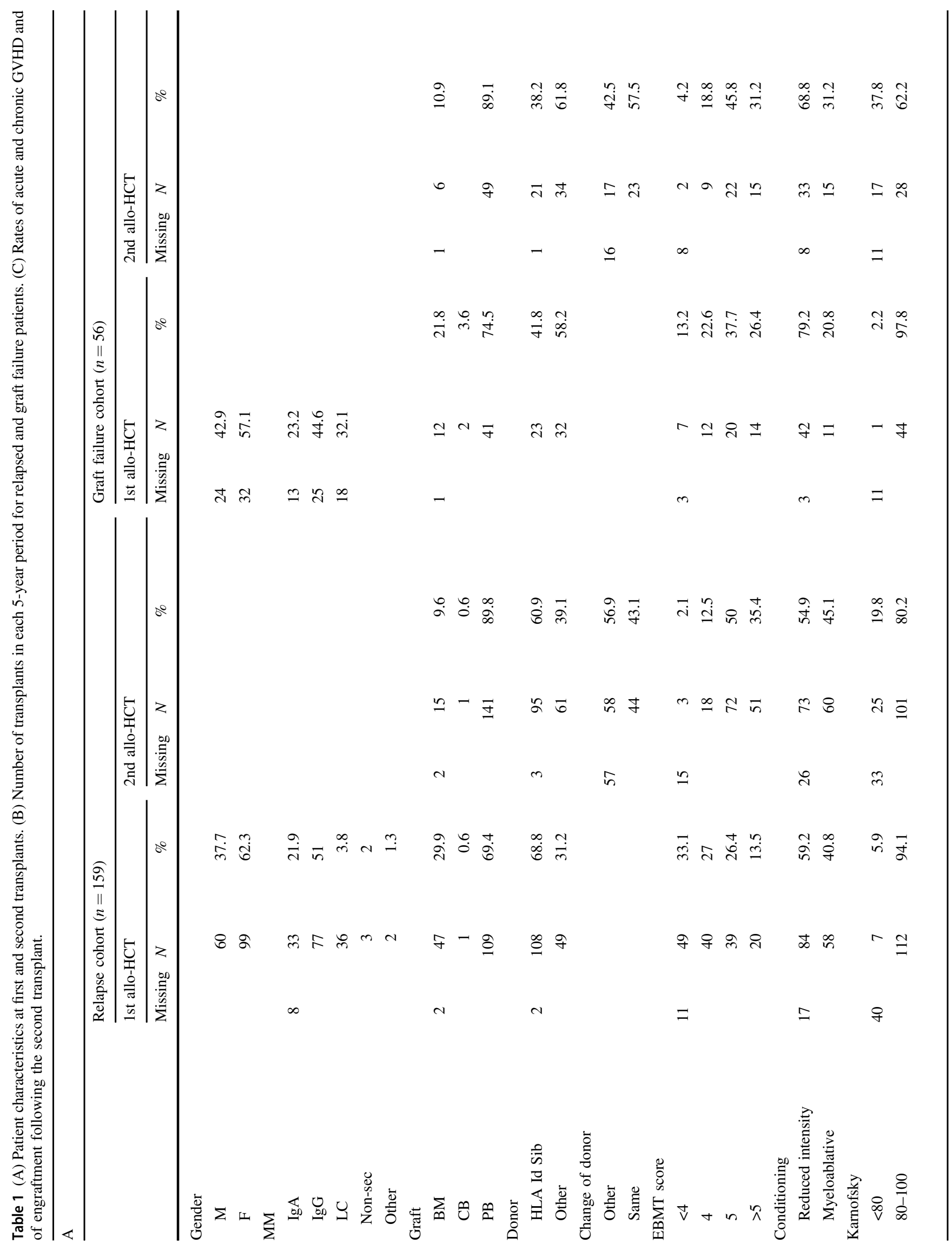




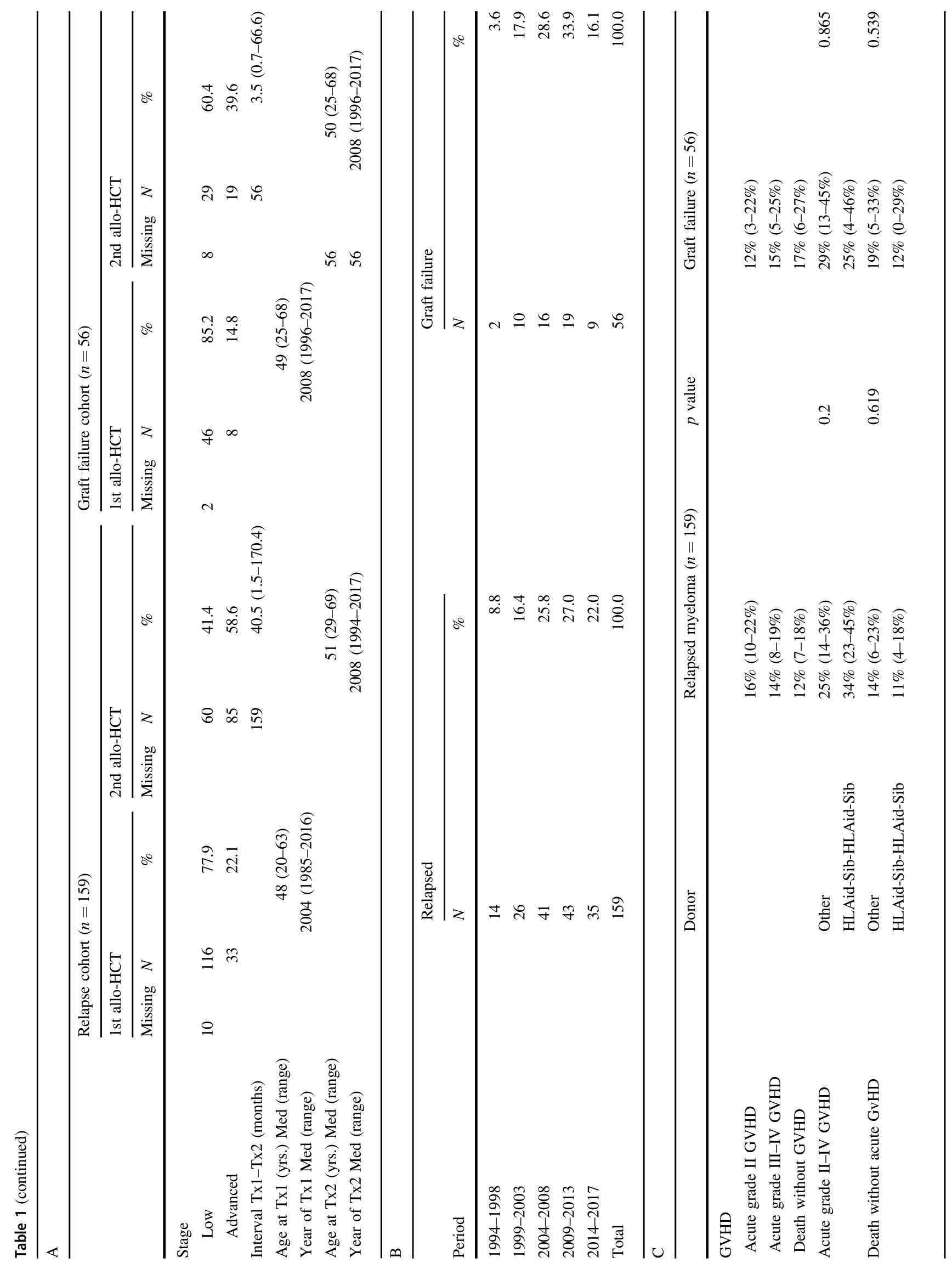




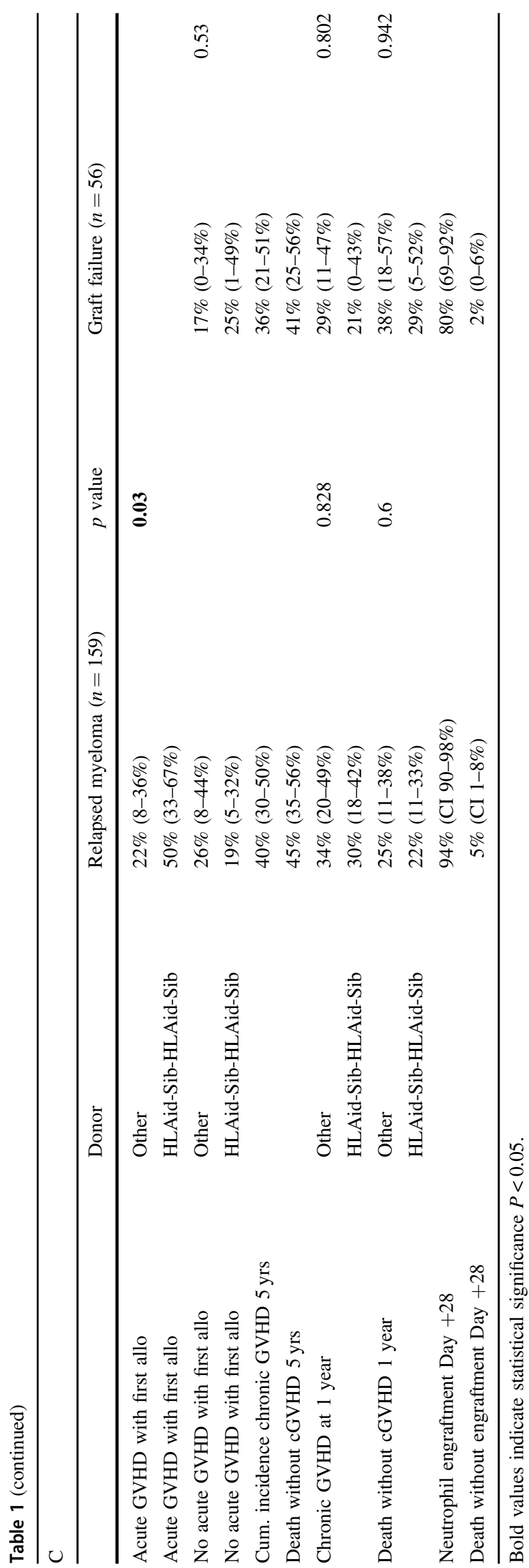

PFS was $17 \%$ (CI 10-23\%) at 2 years post transplant and $6 \%(1-11 \%)$ at 5 years (Fig. 1d). There was no significant difference in PFS between male and female patients. PFS was significantly superior at 2 years when HLA-identical sibling donors were used for both transplants $(24 \%$ $(15-34 \%)$ vs. $3 \%(0-7 \%), p<0.001)$ (Fig. 1e). Significantly inferior PFS at 24 months was seen in those who proceeded to a second allo-HCT within 2 years (9\% (0-18\%) vs. $20 \%$ (12-28\%), $p=0.02$ ) (Fig. 1f).

\section{Relapse incidence/non-relapse mortality}

Relapse Incidence (RI) and NRM rates in patients transplanted for relapsed MM are shown in Table 2. The RI and NRM at 2 and 5 years are shown in Fig. 2 a.

Disease status affected RI and NRM. The incidence of relapse was significantly higher at 2 years $(77 \%$ (68-87\%) vs. $57 \%(44-71 \%))(p=0.009)$ in patients with advanced disease (Fig. 2c). Conversely, the cumulative NRM was significantly higher at 2 years $(25 \%(13-37 \%)$ vs. $11 \%(4-18 \%)(p=$ 0.03)) in patients with low disease burden (Fig. 2c). Older age at second allo-HCT (50-70 vs. $<50$ years) was associated with a higher RI at 2 years (77\% (67-87\%) vs. $56 \%$ $(43-69 \%), p=0.021)$ and the cumulative NRM was significantly higher in younger individuals at 2 years $(24 \%$ $(13-35 \%)$ vs. $9 \%(3-15 \%))(p=0.018)$ (Fig. $2 d)$.

\section{Multivariate analysis}

Multivariate analysis results are shown in Table 3.

When adjusting for the indicated covariates, patients who received both their first and second transplants from HLAidentical siblings had better OS (HR $=0.4$ (0.24-0.67), $p<$ $0.001)$ and PFS $(\mathrm{HR}=0.53(0.31-0.91))$ than other combinations. The risk of relapse was higher in those with more advanced disease (1.85 (1.05-3.24)), $p=0.033)$ and when there was a shorter interval between transplants $(0.88$ (0.79-0.98), $p=0.019)$.

\section{Patients transplanted for graft failure}

\section{Conditioning and GVHD prophylaxis}

Conditioning regimens used in patients with graft failure were mostly fludarabine-based, included Fludarabine and Busulphan \pm ATG (24\%), Fludarabine and Melphalan \pm ATG (22\%), Fludarabine and Cyclophosphamide \pm ATG (14\%) and single agent Fludarabine (14\%). A total of $14 \%$ of patients in whom data was available were conditioned with Cyclophosphamide \pm ATG or Alemtuzumab.

GVHD prophylaxis consisted of cyclosporin-based approaches in $93 \%$ of patients in whom data was available, including cyclosporin and methotrexate (MTX) 


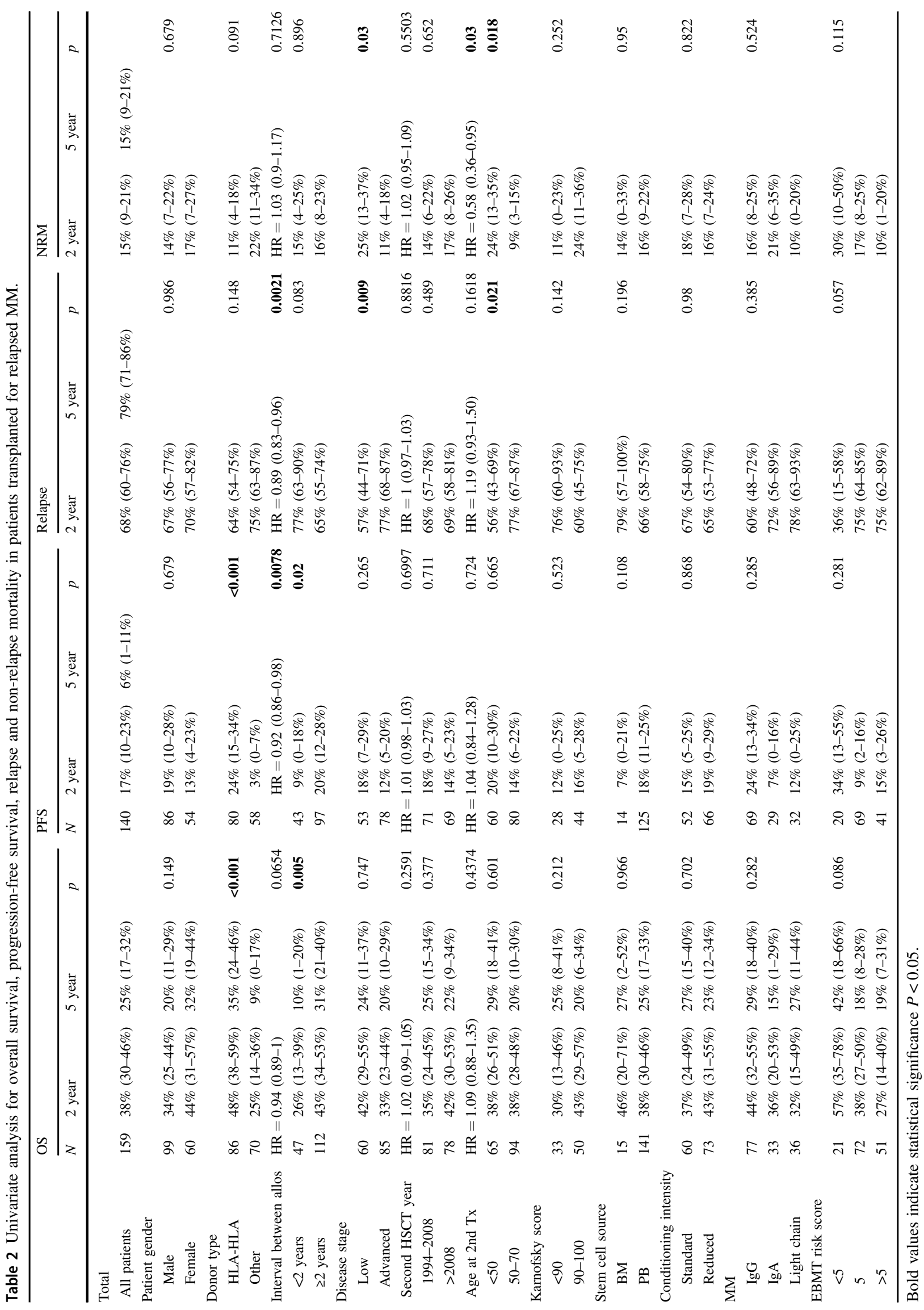



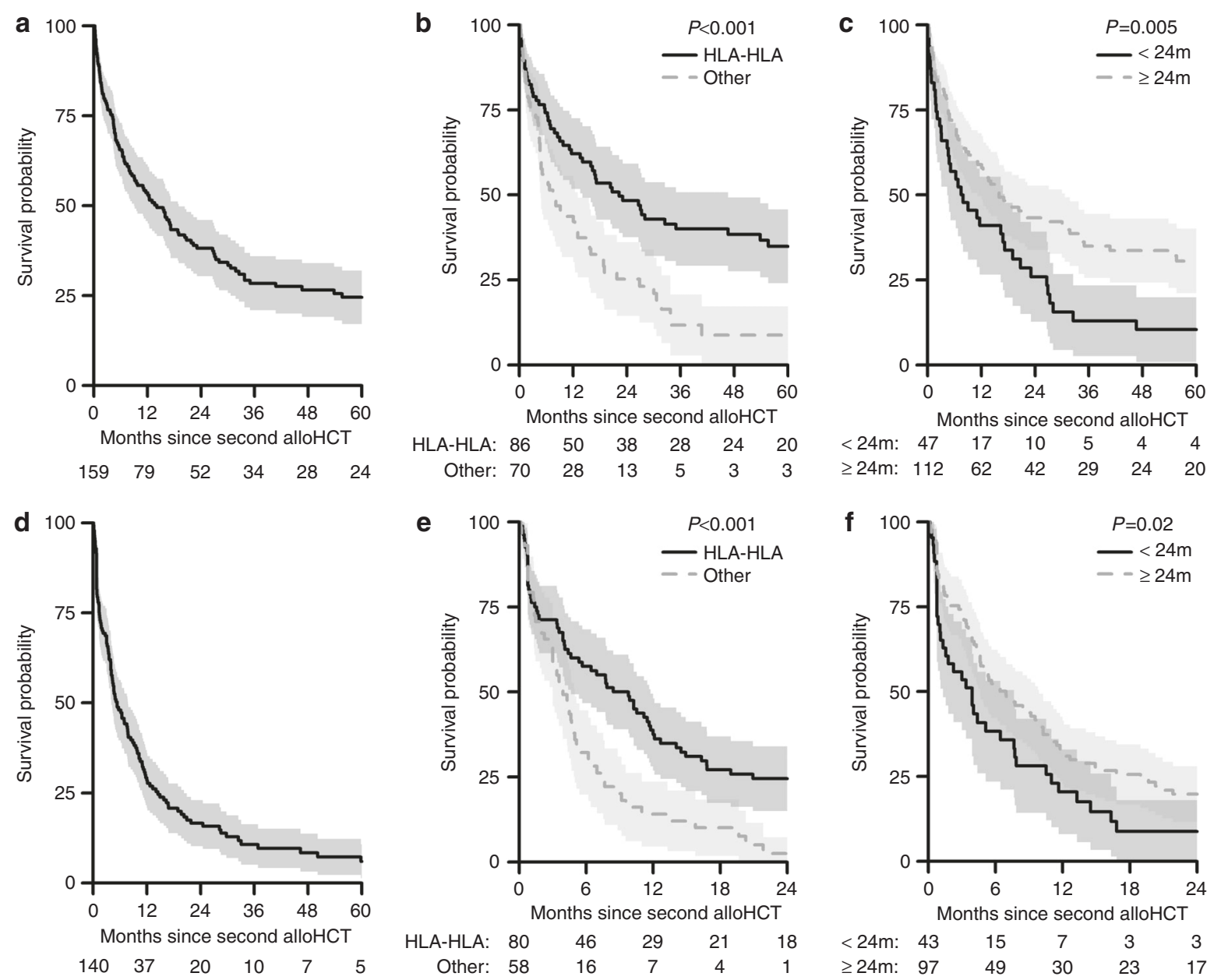

Fig. 1 Overall and Progression-Free Survival following a second allogeneic transplant for relapsed myeloma and factors affecting these outcomes. a Overall survival of patients who underwent a second allo-HCT for relapsed myeloma. b Overall survival of patients who had two consecutive HLA-identical sibling donor transplants (HLA-HLA) versus other donor types. c Overall survival of patients who underwent a second allo-HCT for relapsed myeloma based on

time between first and second allo-HCT (2-year cut-off). d Progression-free survival of patients who underwent a second alloHCT for relapsed myeloma. e Progression-free survival of patients who had two consecutive HLA-identical sibling donor transplants (HLA-HLA) versus other donor types. f Progression-free survival of patients who underwent a second allo-HCT for relapsed myeloma based on time between first and second allo-HCT (2-year cut-off).

(28\%), cyclosporin and MMF (26\%) and single agent cyclosporin $(30 \%)$.

\section{Graft-versus-host disease}

In the first 100 days following the second allo-HCT, the rate of grade II acute GvHD was $12 \%(3-22 \%)$ ), grade III-IV acute GVHD 15\% (5-25\%)) and death without GvHD 17\% (6-27\%)). The 2-year cumulative incidence of chronic GvHD was $36 \%(21-51 \%)$ ) and death without chronic GvHD $41 \%(25-56 \%))$.

\section{Overall survival and progression-free survival}

OS was $41 \%$ (CI 28-54\%) and PFS 34\% (CI 21-47\%) at 2 years post-transplant (Fig. 3a). Univariate analysis of factors potentially affecting OS and PFS is shown in Table 4. None of these factors affected outcomes. The causes of death are shown in Table 5.

\section{Relapse/non-relapse mortality}

Two-year relapse and NRM rates in patients transplanted for graft failure are shown in Table 4 and Fig. 3b. After 2 years, the cumulative RI was $32 \%(19-45 \%)$ ) and NRM $34 \%(21-47 \%)$. The 2-year incidence of relapse based on disease stage is shown in Fig. 3c.

In addition, NRM at 2 years was higher in those with a low disease burden when compared to those with an advanced disease burden $((50 \%)(31-69 \%)$ vs. $12 \%$ $(0-27 \%)(p=0.016)$ (Fig. 3d). 
a

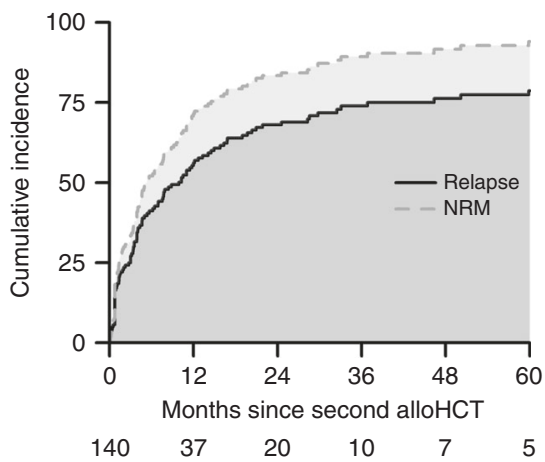

C

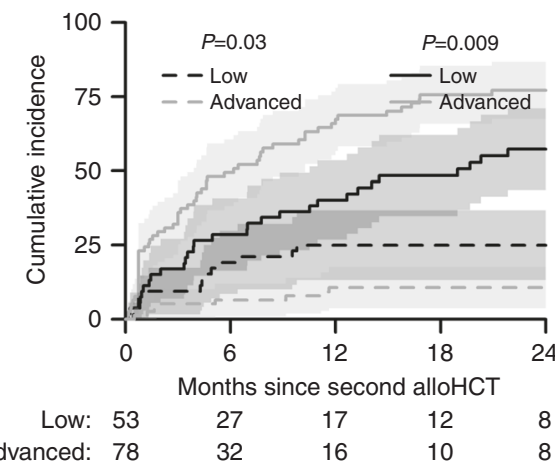

Fig. 2 Relapse incidence and NRM rates following a second allogeneic transplant for relapsed myeloma and factors affecting these outcomes. a Cumulative incidence of relapse (solid line) and nonrelapse mortality (dashed line) over 5 years in patients whose second allo-HCT was for relapsed myeloma. b Cumulative incidence of relapse (solid line) and non-relapse mortality (dashed line) over 5 years based on the type of stem cell donor (HLA-HLA) in patients whose

\section{Discussion}

This is the first registry report of outcomes following second allo-HCT in patients with myeloma. In this analysis, the indications for re-transplantation fell into two groups: relapse and graft failure. In the relapse group, OS was 38\% at 2 years and $25 \%$ at 5 years. This is marginally better than the aggregate 20\% 5-year OS rate reported by Ruutu and colleagues for all 2632 second allogeneic transplants performed in EBMT centres for disease relapse between 1994 and 2009 [13]. In that EBMT registry study, the use of a HLA-identical sibling donor for the second transplant was found to be a favourable predictive factor for OS with a 5year OS probability of $22 \%$ as opposed to $17 \%$ using either other related or unrelated donors $(P=0.012)$. However, whether the same or a new donor was used for the second transplant appeared to make no difference.

In order to more clearly assess these overlapping and potentially confounding categories (HLA-matched versus non-HLA-matched, same donor versus change of donor), we focused on the outcomes of patients who had received both their first and second transplants from HLA-identical sibling donors. Based on the available registry data, over b

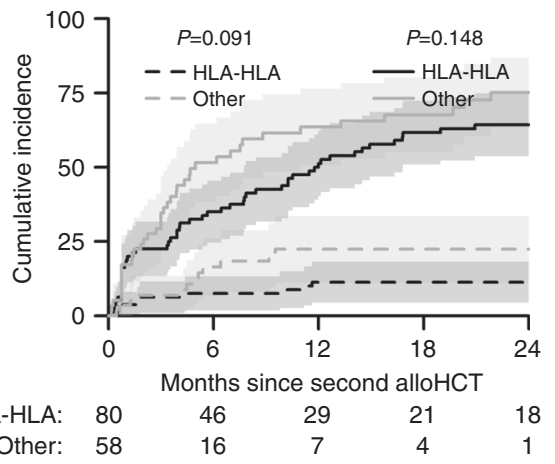

d

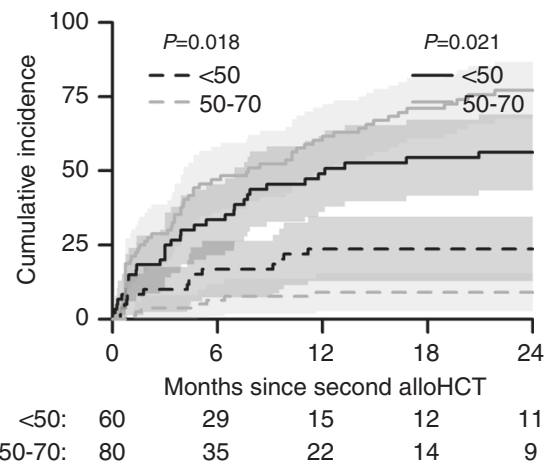

second allo-HCT was for relapsed myeloma. c Cumulative incidence of relapse (solid line) and non-relapse mortality (dashed line) over 5 years based on Disease Stage (low or advanced) in patients whose second allo-HCT was for relapsed myeloma. d Cumulative incidence of relapse (solid line) and non-relapse mortality (dashed line) over 5 years based on age of transplant recipient in patients whose second allo-HCT was for relapsed myeloma.

four-fifths of these patients had the same HLA-identical sibling donor for the two transplants.

In our cohort, patients who had two consecutive HLAidentical sibling donor transplants had better PFS at 2 years ( $24 \%$ vs. $3 \%, p=<0.001)$ and OS at 5 years (35\% vs. $9 \%$, $P<0.001)$. This was confirmed on multivariate analysis with patients receiving both their first and second transplants from HLA-identical sibling donors having better OS $(\mathrm{HR}=0.4(0.2-0.7), p<0.001)$ and PFS (0.5 (0.3-0.9), $p$ $=0.022$ ). Conversely, there were no survivors among the eight patients who had the same donor of any other category (all donor types except for HLA-identical sibling) for both transplants. The positive effect of keeping the same donor, therefore, appears to depend on the specific donor type rather than the individual stem cell donor. One interpretation of these results might be that any additional alloimmune effect conferred by the use of an unrelated donor in transplantation for myeloma is outweighed by greater NRM. In those relapsed patients who had developed acute grade II-IV GVHD following their first allo-HCT, there was a significantly higher incidence of acute grade II-IV GvHD when the same HLA identical sibling donor was used again (50\% vs. $22 \%, p=0.03$ ). 


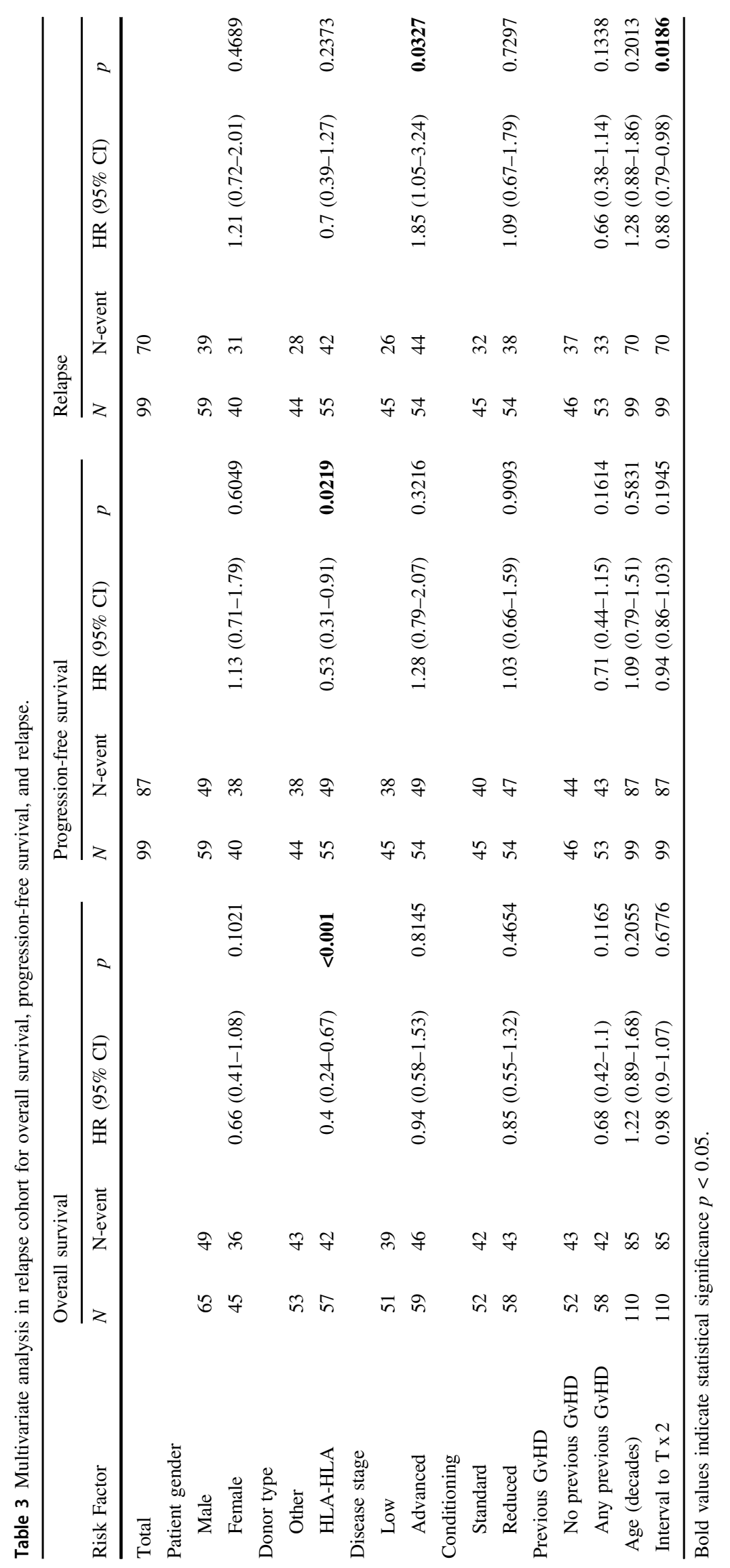


Fig. 3 Overall and

Progression-Free Survival in patients with myeloma following a second allogeneic transplant for graft failure and factors affecting these outcomes. a Two-year overall survival and progression-free survival of MM patients who underwent a second allo-HCT for graft failure. b Cumulative incidence of relapse (solid line) and non-relapse mortality (dashed line) over 2 years in MM patients whose second alloHCT was for graft failure. c Two-year cumulative incidence of relapse based on disease stage (low or advanced) in MM patients whose second allo-HCT was for graft failure. d TwoYear cumulative incidence of non-relapse mortality based on disease stage (low or advanced) in MM patients whose second allo-HCT was for graft failure.
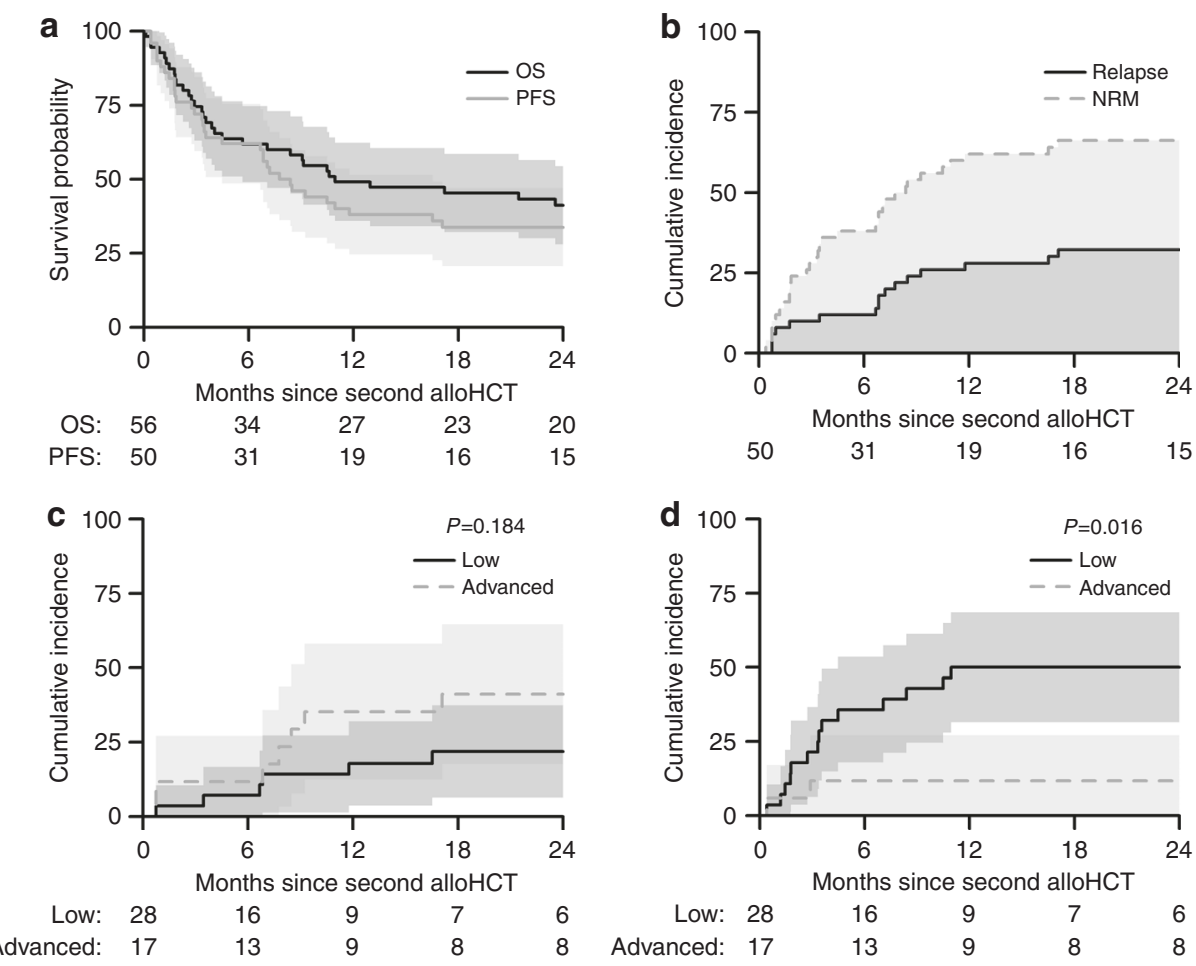

Among patients who have a second allo-HCT for relapsed disease, those with shorter remissions following their first transplant have consistently been reported to have poorer outcomes [5, 6, 12, 18, 19]. This likely reflects both the earlier relapse of biologically more aggressive disease and the cumulative effect of treatmentrelated toxicity. The median interval between transplants in our relapse cohort was over 3 years. Those patients with relapsed disease who proceeded to a second alloHCT within 2 years had a shorter PFS at 2 years (9\% vs. $20 \%, p=0.02)$ as well as a poorer OS at 5 years $(10 \%$ vs. $31 \%, p=0.005)$ when compared to those transplanted more than 2 years later. Also consistent with past reports, the relapse incidence at 2 years was higher (77\% vs. 57\%, $p=0.009$ ) in patients whose disease was in less than a partial remission pre-transplant, when compared to those with a lower disease burden prior to the second transplant [6].

The use of either myeloablative conditioning or RIC prior to a first allo-HCT in patients with myeloma was recently reported to result in similar outcomes [20, 21]. Most of the acute leukemia literature favours the use of RIC in second allogeneic transplants due to lower NRM. In our relapse cohort, $59 \%$ of the first and $55 \%$ of the second transplants were performed following RIC. In the graft failure cohort, the equivalent percentages were $79 \%$ and $69 \%$, respectively. Relapse was more common in older patients (50-70 years) though this did not reflect the intensity of conditioning as there was no difference in the frequency of use of reduced intensity conditioning approaches between the younger and older cohorts.

The causes of death differed between the relapse and graft failure cohorts. A total of 55\% of the relapse group died of 'relapse/disease progression' as opposed to $20 \%$ of infection and 3\% of organ damage/failure and toxicity. In the graft failure group, $23 \%$ died of subsequent relapse/disease progression, $32 \%$ of infection and $16 \%$ of organ damage/failure and toxicity. The shorter time between transplants and the prolonged neutropenia in the setting of graft failure are likely factors in this increased toxicity.

In the graft failure group, OS was $41 \%$ at 2 years. The NRM rate at 2 years in those patients whose myeloma was in a partial remission or better pre-transplant, was $50.2 \%$ (31-69\%) compared to $12 \%(0-27 \%)$ in patients with a higher disease burden $(p=0.016)$. No other variable was found to significantly affect outcomes though this may partially reflect the relatively small patient cohort.

Although second allo-HCT is feasible in myeloma patients, OS outcomes remain poor. There is a need for strategies to achieve deeper remissions prior to any second allo-HCT. A focus on novel maintenance strategies to reduce the risk of relapse is also required [22, 23]. In a CIBMTR comparison of post-relapse OS after autologous/ allogeneic (auto/allo) as opposed to tandem autologous (auto/auto) transplantation between 2000 and 2010, there was superior OS following relapse in auto/allo HCT recipients compared with auto/auto HCT recipients [24]. The 
Table 4 Univariate analyses for Overall Survival, Progression-Free Survival, Relapse and NRM in patients transplanted for graft failure.

\begin{tabular}{|c|c|c|c|c|c|c|c|c|c|c|}
\hline & \multicolumn{3}{|c|}{ Overall survival } & \multicolumn{3}{|c|}{ Progression-free survival } & \multicolumn{2}{|l|}{ Relapse } & \multicolumn{2}{|c|}{ Non-relapse mortality } \\
\hline & $N$ & 2 years & $p$ value & $N$ & 2 years & $p$ value & 2 years & $p$ value & 2 years & $p$ value \\
\hline All & 56 & $41 \%(28-54 \%)$ & & 50 & $34 \%(21-47 \%)$ & & $32 \%(19-45 \%)$ & & $34 \%(21-47 \%)$ & \\
\hline \multicolumn{11}{|l|}{ Patient gender } \\
\hline Male & 24 & $41 \%(21-61 \%)$ & 0.771 & 22 & $31 \%(12-51 \%)$ & 0.925 & $28 \%(9-47 \%)$ & 0.538 & $41 \%(20-61 \%)$ & 0.489 \\
\hline Female & 32 & $41 \%(24-59 \%)$ & & 28 & $36 \%(18-53 \%)$ & & $36 \%(18-53 \%)$ & & $29 \%(12-45 \%)$ & \\
\hline \multicolumn{11}{|l|}{ Donor type } \\
\hline HLAid-Sib-HLAid-Sib & 20 & $32 \%(11-52 \%)$ & 0.699 & 18 & $28 \%(7-48 \%)$ & 0.699 & $39 \%(16-61 \%)$ & 0.429 & $33 \%(12-55 \%)$ & 0.726 \\
\hline Other & 34 & $47 \%(30-64 \%)$ & & 31 & $35 \%(18-52 \%)$ & & $29 \%(13-45 \%)$ & & $35 \%(19-52 \%)$ & \\
\hline \multicolumn{11}{|l|}{ Interval between allos } \\
\hline$<1$ year & 44 & $37 \%(22-51 \%)$ & 0.266 & 38 & $37 \%(22-52 \%)$ & 0.585 & $26 \%(12-40 \%)$ & 0.147 & $37 \%(22-52 \%)$ & 0.567 \\
\hline$\geq 1$ year & 12 & $58 \%(30-86 \%)$ & & 12 & $25 \%(1-49 \%)$ & & $50 \%(22-78 \%)$ & & $25 \%(1-49 \%)$ & \\
\hline \multicolumn{11}{|l|}{ Disease status } \\
\hline Low & 29 & $37 \%(19-55 \%)$ & 0.147 & 28 & $28 \%(11-45 \%)$ & 0.21 & $22 \%(6-37 \%)$ & 0.184 & $50 \%(31-69 \%)$ & 0.016 \\
\hline Advanced & 19 & $61 \%(39-84 \%)$ & & 17 & $47 \%(23-71 \%)$ & & $41 \%(18-65 \%)$ & & $12 \%(0-27 \%)$ & \\
\hline \multicolumn{11}{|l|}{ Year at second allo } \\
\hline 1994-2008 & 28 & $33 \%(15-51 \%)$ & 0.341 & 23 & $39 \%(19-59 \%)$ & 0.458 & $22 \%(5-39 \%)$ & 0.191 & $39 \%(19-59 \%)$ & 0.65 \\
\hline After 2008 & 28 & $49 \%(30-68 \%)$ & & 27 & $30 \%(12-47 \%)$ & & $41 \%(22-59 \%)$ & & $30 \%(12-47 \%)$ & \\
\hline \multicolumn{11}{|l|}{ Age at second allo } \\
\hline$<50$ years & 29 & $44 \%(26-63 \%)$ & 0.868 & 27 & $37 \%(19-55 \%)$ & 0.873 & $30 \%(12-47 \%)$ & 0.816 & $33 \%(16-51 \%)$ & 0.942 \\
\hline $50-70$ years & 27 & $38 \%(19-57 \%)$ & & 23 & $30 \%(12-49 \%)$ & & $35 \%(15-54 \%)$ & & $35 \%(15-54 \%)$ & \\
\hline \multicolumn{11}{|l|}{ Karnofsky score } \\
\hline$<90$ & 13 & $62 \%(35-88 \%)$ & 0.345 & 13 & $38 \%(12-65 \%)$ & 0.488 & $38 \%(12-65 \%)$ & 0.684 & $23 \%(0-46 \%)$ & 0.269 \\
\hline $90-100$ & 16 & $42 \%(16-67 \%)$ & & 16 & $25 \%(4-46 \%)$ & & $31 \%(9-54 \%)$ & & $44 \%(19-68 \%)$ & \\
\hline \multicolumn{11}{|l|}{ Stem cell source } \\
\hline $\mathrm{BM}$ & 6 & $50 \%(10-90 \%)$ & 0.582 & 6 & $50 \%(10-90 \%)$ & 0.349 & $17 \%(0-46 \%)$ & 0.367 & $33 \%(0-71 \%)$ & 0.904 \\
\hline PB & 49 & $39 \%(25-53 \%)$ & & 43 & $30 \%(16-44 \%)$ & & $35 \%(21-50 \%)$ & & $35 \%(21-49 \%)$ & \\
\hline \multicolumn{11}{|l|}{ Conditioning intensity } \\
\hline Standard & 15 & $39 \%(14-64 \%)$ & 0.823 & 12 & $33 \%(7-60 \%)$ & 0.845 & $42 \%(14-70 \%)$ & 0.754 & $25 \%(1-49 \%)$ & 0.711 \\
\hline Reduced & 33 & $46 \%(29-64 \%)$ & & 30 & $36 \%(19-54 \%)$ & & $34 \%(17-51 \%)$ & & $30 \%(14-46 \%)$ & \\
\hline \multicolumn{11}{|l|}{ MM } \\
\hline IgG & 25 & $44 \%(25-63 \%)$ & 0.834 & 22 & $40 \%(20-61 \%)$ & 0.629 & $28 \%(9-47 \%)$ & 0.637 & $32 \%(12-51 \%)$ & 0.879 \\
\hline $\operatorname{Ig} \mathrm{A}$ & 13 & $31 \%(6-56 \%)$ & & 12 & $25 \%(1-49 \%)$ & & $42 \%(14-70 \%)$ & & $33 \%(7-60 \%)$ & \\
\hline Light chain & 18 & $46 \%(22-70 \%)$ & & 16 & $31 \%(9-54 \%)$ & & $31 \%(9-54 \%)$ & & $38 \%(14-61 \%)$ & \\
\hline \multicolumn{11}{|l|}{ EBMT risk score } \\
\hline$<5$ & 11 & $34 \%(5-63 \%)$ & 0.682 & 11 & $34 \%(5-63 \%)$ & 0.867 & $20 \%(0-46 \%)$ & 0.527 & $45 \%(16-75 \%)$ & 0.826 \\
\hline 5 & 22 & $43 \%(22-64 \%)$ & & 19 & $37 \%(15-59 \%)$ & & $32 \%(11-52 \%)$ & & $32 \%(11-52 \%)$ & \\
\hline$>5$ & 15 & $52 \%(27-78 \%)$ & & 15 & $27 \%(4-49 \%)$ & & $40 \%(15-65 \%)$ & & $33 \%(9-57 \%)$ & \\
\hline
\end{tabular}

Bold values indicate statistical significance $p<0.05$.

authors contended that this reflected a better response to salvage with agents such as immunomodulatory drugs in the context of donor-derived immunity. This detailed information is unfortunately not available to allow us to analyse the relevance of such factors in our cohort. Nonetheless, small molecule inhibitors and novel immunotherapies have the potential to change the kinetics of disease relapse, thereby facilitate an emerging alloimmune graft-versus-malignancy response post transplant.
Myeloma patients who relapse post-transplant often retain full donor chimerism. In this setting, Novak and colleagues reported on second "allogeneic" transplants using CD34+ selected donor cells without immunosuppression followed by DLI and/or maintenance therapy as a means of achieving disease control [17]. Myeloablative conditioning was well tolerated with no NRM and no GVHD. OS was $100 \%$ at 1 year and $69 \%$ at 2 years though PFS was only $13 \%$ at 2 years. 
Table 5 Causes of death within the follow-up period: 5 years for relapse, 2 years for graft failure.

\begin{tabular}{|c|c|c|c|c|c|c|}
\hline \multirow[t]{2}{*}{ Causes of death } & \multicolumn{3}{|c|}{ Relapsed myeloma } & \multicolumn{3}{|c|}{ Graft failure } \\
\hline & Missing & Frequency & Percent & Missing & Frequency & Percent \\
\hline Relapse/disease progression & 3 & 59 & 55.1 & 1 & 7 & 22.6 \\
\hline Secondary malignancy/PTLD & & 2 & 1.9 & & & \\
\hline GVHD & & 12 & 11.2 & & 4 & 12.9 \\
\hline Infection & & 21 & 19.6 & & 10 & 32.3 \\
\hline Organ damage/failure & & 2 & 1.9 & & 3 & 9.7 \\
\hline Toxicity & & 1 & 0.9 & & 2 & 6.5 \\
\hline HSCT-related death & & 5 & 4.7 & & 2 & 6.5 \\
\hline Other & & 5 & 4.7 & & 3 & 9.7 \\
\hline Total & & 110 & & & 32 & \\
\hline
\end{tabular}

This may represent another salvage treatment option in selected patients.

There are some weaknesses in our study. The disease staging system, an EBMT remission-based classification, is not specific to myeloma and it is surprising that there is no difference in OS or PFS between those with 'Low' as opposed to 'Advanced' disease. It is possible that the very high rates of post-transplant relapse-overall PFS was $6 \%$ $(1-11 \%)$ at 5 years in patients transplanted for relapsed myeloma-may have masked any PFS difference. In addition, OS will have been affected by subsequent salvage treatments. However, there is a signal of their 'Advanced' disease status is that these patients have a significantly higher relapse rate on both univariate and multivariate analysis.

In summary, one quarter of myeloma patients remained alive 5 years following a second allogeneic haematopoietic cell transplant with similar outcomes seen following disease relapse and graft failure. The best outcomes (35\% OS at 5 years) were seen in those who had two consecutive HLAidentical sibling donor transplants.

Acknowledgements We would like to acknowledge the support of the EBMT Leiden office and all participating transplant centres.

Funding Open Access funding provided by the IReL Consortium.

\section{Compliance with ethical standards}

Conflict of interest The authors declare no competing interests.

Publisher's note Springer Nature remains neutral with regard to jurisdictional claims in published maps and institutional affiliations.

Open Access This article is licensed under a Creative Commons Attribution 4.0 International License, which permits use, sharing, adaptation, distribution and reproduction in any medium or format, as long as you give appropriate credit to the original author(s) and the source, provide a link to the Creative Commons license, and indicate if changes were made. The images or other third party material in this article are included in the article's Creative Commons license, unless indicated otherwise in a credit line to the material. If material is not included in the article's Creative Commons license and your intended use is not permitted by statutory regulation or exceeds the permitted use, you will need to obtain permission directly from the copyright holder. To view a copy of this license, visit http://creativecommons. org/licenses/by/4.0/.

\section{Contributors}

Yves Beguin, University of Liege, Liege, Belgium; Jean Henri Bourhis, Gustave Roussy Cancer Campus, Villejuif, France; Peter Dreger, University of Heidelberg, Heidelberg, Germany; Franca Fagioli, Onco-Ematologia Pediatrica, Torino, Italy; Jürgen Finke, University of Freiburg, Freiburg, Germany; Hélène Labussière-Wallet, Centre Hospitalier Lyon Sud, Lyon, France; Matjaz Sever, University Med. Center, Ljubljana, Slovenia; Gwendolyn Van Gorkom, University Hospital Maastricht, Maastricht, Netherlands; Jane Apperley, Imperial College, London, UK; Wolfgang Bethge, Universitaet Tuebingen, Tuebingen, Germany; Didier Blaise, Programme de Transplantation\&Therapie Cellulaire, Marseille, France; Francesca Bonifazi, Bologna University, S.Orsola-Malpighi Hospital, Bologna, Italy; Prof. J.J. Cornelissen, Erasmus MC Cancer Institute, Rotterdam, Netherlands; Ahmet Elmaagacli, Asklepios Klinik St. Georg, Hamburg, Germany; John Gribben, St. Bartholomew's and The Royal London NHS Trust, London, UK; Maija Itäla-Remes, Turku University Hospital, Turku, Finland; Yener Koc, Medicana International Hospital Istanbul, Istanbul, Turkey; Xavier Leleu, Hopital La Miletrie, Poitiers, France; Giuseppe Marotta, U. O.S.A Centro Trapianti e Terapia Cellulare, Siena, Italy; Francesco Onida, Fondazione IRCCS - Ca' Granda, Milano, Italy; Kim Orchard, Southampton General Hospital, Southampton, UK; Dominik Selleslag, A.Z. Sint-Jan, Brugge, Belgium; Lorenz Thurner, University of Saarland, Homburg, Germany; Dominik Wolf, University Hospital Innsbruck, Innsbruck, Austria; Gerald. G. Wulf, Universitaetsklinikum Goettingen, Goettingen, Germany; 
Ibrahim Yakoub-Agha, CHU de Lille, Lille, France; Adrián Alegre Amor, Hospital de la Princesa, Madrid, Spain; Achilles Anagnostopoulos, George Papanicolaou General Hospital, Thessaloniki, Greece; Grzegorz Basak, Central Clinical Hospital, Warsaw, Poland; Jacques-Olivier Bay, CHU ESTAING, Clermont_Ferr, France; Martin Bornhäuser, Universitaetsklinikum Dresden, Dresden, Germany; Claude Eric Bulabois, CHU Grenoble Alpes Université Grenoble Alpes, Grenoble, France; Dolores Caballero, Hospital Clínico, Salamanca, Spain; Thomas Cluzeau, CHU Nice - Hôpital de l'ARCHET I, Nice, France; Matthew Collin, Adult HSCT unit, Newcastle_Tyne, UK; Paolo Corradini, University of Milano, Milano, Italy; Charles Craddock, University Hospital Birmingham NHSTrust, Birmingham, UK; Eric Deconinck, Hopital Jean Minjoz, Besancon, France; J.L. Diez-Martin, Hospital Gregorio Marañón, Madrid, Spain; Matthias Edinger, University Regensburg, Regensburg, Germany; Tobias Gedde-Dahl, Oslo University Hospital, Rikshospitalet, Oslo, Norway; Cecilia Isaksson, Umea University Hospital, Umea, Sweden; Wu Ka Lung, ZNA, Antwerp, Belgium; Tessa Kerre, Ghent University Hospital, Gent, Belgium; Anjum Khan, Yorkshire Blood \& Marrow Transplant Programme, Leeds, UK; Guido Kobbe, Heinrich Heine Universitaet, Duesseldorf, Germany; Giorgio La Nasa, Centro Trapianti Unico Di CSE Adulti e Pediatrico A. O Brotzu, Cagliari, Italy; Andrzej Lange, DCTK, Wroclaw, Poland; Murray Martin, Leicester Royal Infirmary, Leicester, UK; Ellen Meijer, VU University Medical Center, Amsterdam, Netherlands; Mohamad Mohty, Hopital Saint Antoine, Paris, France; Nicola Mordini, Az. Ospedaliera S. Croce e Carle, Cuneo, Italy; Arnon Nagler, Chaim Sheba Medical Center, Tel_Hashomer, Israel; Zubeyde Nur Ozkurt, Gazi University Faculty of Medicine, Ankara, Turkey; Amit Patel, Clatterbridge Cancer Centre Liverpool, Royal Liverpool University Hospital, Liverpool, UK; Victoria Potter, Kings College Hospital, London, UK; Ron Ram, Tel Aviv Sourasky Medical Center, Tel_Aviv, Israel; Alessandro Rambaldi, ASST Papa Giovanni XXIII, Bergamo, Italy; Christian Reinhardt, University Hospital, Essen, Germany; Riccardo Saccardi, Azienda Ospedaliera Universitaria Careggi, Firenze, Italy; Jaime Sanz, University Hospital La Fe, Valencia, Spain; Urs Schanz, University Hospital, Zurich, Switzerland; Christof Scheid, University of Cologne, Cologne, Germany; Kerstin SchäferEckart, Klinikum Nuernberg, Nuernberg, Germany; Rosanna Scimè, U.O.D Trapianti di midollo osseo, Palermo, Italy; Henrik Sengeloev, Bone Marrow Transplant Unit L 4043, Copenhagen, Denmark; Simona Sica, Universita Cattolica S. Cuore, Rome, Italy; Gerard Socié, Hopital St. Louis, Paris, France; Abdelghani Tbakhi, King Hussein Cancer Centre, Amman, Jordan; Herve Tilly, Centre Henri Becquerel, Rouen, France; Thomas Valerius,
University Medical Center Schleswig-Holstein, Campus Kiel, Kiel, Germany; Andrea Velardi, Sezione di Ematologia, Perugia, Italy; Jan Vydra, Institute of Hematology and Blood Transfusion, Prague, Czech Rep; Eva Maria Wagner-Drouet, University Medical Center Mainz, Mainz, Germany; Jan Walewski, Maria Sklodowska-Curie Institute - Oncology Centre, Warsaw, Poland; Pavel Zák, Charles University Hospital, Hradec_Kralove, Czech Rep.

\section{References}

1. Craddock C, Hoelzer D, Komanduri KV. Current status and future clinical directions in the prevention and treatment of relapse following hematopoietic transplantation for acute myeloid and lymphoblastic leukemia. Bone Marrow Transpl. 2019;54:6-16. https://doi.org/10.1038/s41409-018-0203-8. e-pub ahead of print 2018/06/02

2. Sureda A, Dreger P, Bishop MR, Kroger N, Porter DL. Prevention and treatment of relapse after stem cell transplantation in lymphoid malignancies. Bone Marrow Transpl. 2019;54:17-25. https://doi.org/10.1038/s41409-018-0214-5. e-pub ahead of print 2018/05/26

3. Chen YB, McCarthy PL, Hahn T, Holstein SA, Ueda M, Kroger N, et al. Methods to prevent and treat relapse after hematopoietic stem cell transplantation with tyrosine kinase inhibitors, immunomodulating drugs, deacetylase inhibitors, and hypomethylating agents. Bone Marrow Transpl. 2019;54:497-507. https://doi.org/10.1038/s41409-018-0269-3. epub ahead of print 2018/07/25

4. Falkenburg F, Ruggiero E, Bonini C, Porter D, Miller J, Malard F, et al. Prevention and treatment of relapse after stem cell transplantation by cellular therapies. Bone Marrow Transpl. 2019;54:26-34. https://doi.org/10.1038/s41409-018-0227-0. epub ahead of print 2018/05/26

5. Shaw BE, Mufti GJ, Mackinnon S, Cavenagh JD, Pearce RM, Towlson KE, et al. Outcome of second allogeneic transplants using reduced-intensity conditioning following relapse of haematological malignancy after an initial allogeneic transplant. Bone Marrow Transpl. 2008;42:783-9. https://doi.org/10.1038/bmt. 2008.255. e-pub ahead of print 2008/08/30

6. Vrhovac R, Labopin M, Ciceri F, Finke J, Holler E, Tischer J, et al. Second reduced intensity conditioning allogeneic transplant as a rescue strategy for acute leukaemia patients who relapse after an initial RIC allogeneic transplantation: analysis of risk factors and treatment outcomes. Bone Marrow Transpl. 2016;51 (2):186-93. https://doi.org/10.1038/bmt.2015.221. e-pub ahead of print 2015/10/06

7. Weisdorf D. The role of second transplants for leukemia. Best Pr Res Clin Haematol. 2016;29:359-64. https://doi.org/10.1016/j. beha.2016.10.011. e-pub ahead of print 2016/11/29

8. Aljasem HA, Messner HA, Lipton JH, Kim DDH, Viswabandya A, Thyagu S, et al. Outcome following second allogeneic hematopoietic cell transplantation: a single-center experience. Eur J Haematol. 2018;100:308-14. https://doi.org/10.1111/ejh.13015. e-pub ahead of print 2017/12/15

9. Moukalled NM, Kharfan-Dabaja MA. What is the role of a second allogeneic hematopoietic cell transplant in relapsed acute myeloid leukemia? Bone Marrow Transpl. 2019. https://doi.org/10.1038/ s41409-019-0584-3. e-pub ahead of print 2019/06/05

10. Shimomura Y, Hara M, Tachibana T, Ohashi K, Sakura T, Fukuda $\mathrm{T}$, et al. Outcomes of second allogeneic haematopoietic stem cell 
transplantation in patients with relapse of myelodysplastic syndrome. Br J Haematol. 2019;186:86-90. https://doi.org/10.1111/ bjh.15898. e-pub ahead of print 2019/04/04

11. Radich JP, Sanders JE, Buckner CD, Martin PJ, Petersen FB, Bensinger $\mathrm{W}$, et al. Second allogeneic marrow transplantation for patients with recurrent leukemia after initial transplant with totalbody irradiation-containing regimens. $\mathrm{J}$ Clin Oncol. 1993;11:304-13. https://doi.org/10.1200/JCO.1993.11.2.304. epub ahead of print 1993/02/01

12. Michallet M, Tanguy ML, Socie G, Thiebaut A, Belhabri A, Milpied N, et al. Second allogeneic haematopoietic stem cell transplantation in relapsed acute and chronic leukaemias for patients who underwent a first allogeneic bone marrow transplantation: a survey of the Societe Francaise de Greffe de moelle (SFGM). Br J Haematol. 2000;108:400-7. https://doi.org/10. 1046/j.1365-2141.2000.01851.x. e-pub ahead of print 2000/02/26

13. Ruutu T, de Wreede LC, van Biezen A, Brand R, Mohty M, Dreger $\mathrm{P}$, et al. Second allogeneic transplantation for relapse of malignant disease: retrospective analysis of outcome and predictive factors by the EBMT. Bone Marrow Transpl. 2015;50:1542-50. https://doi.org/10.1038/bmt.2015.186. e-pub ahead of print $2015 / 09 / 15$

14. Ferra C, Sanz J, Diaz-Perez MA, Morgades M, Gayoso J, Cabrera $\mathrm{JR}$, et al. Outcome of graft failure after allogeneic stem cell transplant: study of 89 patients. Leuk Lymphoma. 2015;56:656-62. https://doi.org/10.3109/10428194.2014.930849. e-pub ahead of print 2014/06/11

15. Lund TC, Liegel J, Bejanyan N, Orchard PJ, Cao Q, Tolar J, et al. Second allogeneic hematopoietic cell transplantation for graft failure: poor outcomes for neutropenic graft failure. Am J Hematol. 2015;90:892-6. https://doi.org/10.1002/ajh.24111. epub ahead of print 2015/07/08

16. Schriber J, Agovi MA, Ho V, Ballen KK, Bacigalupo A, Lazarus $\mathrm{HM}$, et al. Second unrelated donor hematopoietic cell transplantation for primary graft failure. Biol Blood Marrow Transpl. 2010;16:1099-106. https://doi.org/10.1016/j.bbmt.2010.02.013. e-pub ahead of print 2010/02/23

17. Novak P, Klyuchnikov E, von Pein UM, Gullstorf M, Christopeit $\mathrm{M}$, Ayuk F, et al. Second allogeneic stem cell transplantation for relapse after allografting in multiple myeloma using CD 34+ selected donor cells without immunosuppression. Bone Marrow
Transpl. 2020;55:1817-20. https://doi.org/10.1038/s41409-0200912-7. e-pub ahead of print 2020/05/01

18. Kishi K, Takahashi S, Gondo H, Shiobara S, Kanamaru A, Kato $\mathrm{S}$, et al. Second allogeneic bone marrow transplantation for posttransplant leukemia relapse: results of a survey of 66 cases in 24 Japanese institutes. Bone Marrow Transpl. 1997;19:461-6. https:// doi.org/10.1038/sj.bmt.1700680. e-pub ahead of print 1997/03/01

19. Eapen M, Giralt SA, Horowitz MM, Klein JP, Wagner JE, Zhang $\mathrm{MJ}$, et al. Second transplant for acute and chronic leukemia relapsing after first HLA-identical sibling transplant. Bone Marrow Transpl. 2004;34:721-7. https://doi.org/10.1038/sj.bmt. 1704645. e-pub ahead of print 2004/08/24

20. Hayden PJ, Iacobelli S, Perez-Simon JA, van Biezen A, Minnema M, Niittyvuopio R, et al. Conditioning-based outcomes after allogeneic transplantation for myeloma following a prior autologous transplant (1991-2012) on behalf of EBMT CMWP. Eur J Haematol. 2019. https://doi.org/10.1111/ejh.13352. e-pub ahead of print 2019/11/19

21. Maymani H, Lin P, Saliba RM, Popat U, Bashir Q, Shah N, et al. Comparison of outcomes of allogeneic hematopoietic cell transplantation for multiple myeloma using three different conditioning regimens. Biol Blood Marrow Transpl. 2019;25:1039-44. https:// doi.org/10.1016/j.bbmt.2019.01.009. e-pub ahead of print 2019/ $01 / 15$

22. Schneidawind C, Duerr-Stoerzer S, Faul C, Kanz L, Weisel K, Bethge $\mathrm{W}$ et al. Follow-up of patients with refractory or relapsed multiple myeloma after allogeneic hematopoietic cell transplantation. Clin Transplant 2017; 31. https://doi.org/10.1111/ctr. 12994. e-pub ahead of print 2017/05/05

23. Giaccone L, Evangelista A, Patriarca F, Sorasio R, Pini M, Carnevale-Schianca F, et al. Impact of new drugs on the longterm follow-up of upfront tandem autograft-allograft in multiple myeloma. Biol Blood Marrow Transpl. 2018;24:189-93. https:// doi.org/10.1016/j.bbmt.2017.09.017. e-pub ahead of print 2017/ $10 / 11$

24. Htut M, D’Souza A, Krishnan A, Bruno B, Zhang MJ, Fei M, et al. Autologous/allogeneic hematopoietic cell transplantation versus tandem autologous transplantation for multiple myeloma: comparison of long-term postrelapse survival. Biol Blood Marrow Transpl. 2018;24:478-85. https://doi.org/10.1016/j.bbmt.2017.10. 024. e-pub ahead of print $2017 / 10 / 29$ 